\title{
Soil from a Hexachlorocyclohexane Contaminated Field Site Inoculates Wheat in a Pot Experiment to Facilitate the Microbial Transformation of $\beta$-Hexachlorocyclohexane Examined by Compound-Specific Isotope Analysis
}

Xiao $\mathrm{Liu}^{\dagger}$, Wang $\mathrm{Li}^{\dagger}$, , Steffen Kümmel${ }^{\dagger}$, Ines Merbach ${ }^{\S}$, Utkarsh Sood", Vipin Gupta ${ }^{\perp}$, Rup Lal", Hans H. Richnow ${ }^{\dagger, *}$

${ }^{\dagger}$ Department of Isotope Biogeochemistry, Helmholtz Centre for Environmental ResearchUFZ, Permoserstraße 15, 04318 Leipzig, Germany.

${ }^{\ddagger}$ Institute for Applied Geosciences, Technical University Darmstadt, Schnittspahnstraße 9, 64287 Darmstadt, Germany.

${ }^{\S}$ Department of Community Ecology, Helmholtz Centre for Environmental Research GmbH - UFZ, Theodor-Lieser-Str. 4, 06102 Halle, Germany.

" The Energy and Resources Institute, Lodhi Road, New Delhi-110003, India

${ }^{\perp}$ PhiXGen Private Limited, Gurugram, Haryana-122001, India

*Corresponding Author

Address: Department of Isotope Biogeochemistry, Helmholtz Centre for Environmental Research-UFZ, Permoserstraße 15, 04318 Leipzig, Germany. Tel: 00493412351212 .Fax: 0341-450822. Email: hans.richnow@ufz.de

The supporting information contains: 25 pages, 2 tables, 10 figures. 
S1 Chemicals and Materials. The $\beta$-HCH (analytical purity, 99\%) was purchased from Sigma Aldrich (Germany) and has a $\delta^{13} \mathrm{C}$ value of $-25.7 \pm 0.2 \%$ and a $\delta^{37} \mathrm{Cl}$ value of -2.4 $\pm 0.3 \%$. The solvents $n$-hexane $(\geq 99.9 \%$, ROTISOLV HPLC, ROTH) and acetone $(\geq 99.9 \%$, ROTISOLV UV/IR-Grade, ROTH) were used for HCH extraction. Dichloromethane (DCM, $\geq 99.9 \%$, ROTISOLV HPLC, ROTH) was used for the clean-up of soil and plant extracts. Florisil (100-200 mesh, for chromatography, ROTH) was used as stationary phase for liquid column chromatography which was activated at $120{ }^{\circ} \mathrm{C}$ for $12 \mathrm{~h}$ before usage. Anhydrous $\mathrm{Na}_{2} \mathrm{SO}_{4}$ used for drying was activated by heating at $200{ }^{\circ} \mathrm{C}$ overnight. Glass wool (untreated, SUPELCO Analytical) and sea sand were used for packing of chromatographic columns. To track the elution of HCHs from the Florisil column, 7,12-dimethyl-benz[ $\alpha]$ anthracene (p. A, Reagent Grade) was applied as a fluorescence tracer. A $360 \mathrm{~nm}$ UVA lamp was used to visualize the fluorescence band.

S2 Field Site. The Bitterfeld-Wolfen region belongs to former German Democratic Republic territory, located in Eastern Germany, which had been heavily impacted by openpit lignite mining and related carbon-based chemical industry for more than a century until the German reunification in 1989/90 ${ }^{1}$. Beside the industrial manufacture of about 4500 chlorine-based chemical substances or associated consumer goods, HCH and DDT were extensively produced in Bitterfeld-Wolfen between 1951-1982 ${ }^{1}$. Long-term chemical production affected all environmental compartments such as air, soil, subsurface, and groundwater. Former open-pit mines were subsequently used for dumping chemical residues from industrial production without any appropriate safety or environmental protection measurements. Today most of the contaminated soils in the production areas were remediated or stabilized. The soil used for our experiments was from a loading area 
of a former HCH factory. It is a Gleyic Fluvisol locaced at slope of a hillside in a former industrial area partly mixed with dumped gravel and remains from demolition material of former factories. However, in vicinity of the former loading areas next to the factory there are still some hot spots of soils heavily contaminated by muck. The area is covered by trees and bush land today and the trees have an age of more than 20 years implying that the area has been undisturbed for at least this period.

\section{S3 Extraction and Clean-up of HCHs from Soil and Wheat Tissues}

Soil samples were frozen at $-20^{\circ} \mathrm{C}$ overnight and afterwards dried in a freeze-dryer (Christ Beta-2-16 Freeze Dryer, Martin Christ Gefriertrocknungsanlagen GmbH, Germany) at $35^{\circ} \mathrm{C}$ and $0.310 \mathrm{mbar}$ for $48 \mathrm{~h}$. About 6-7 $\mathrm{g}$ freeze-dried soil was extracted by accelerated solvent extraction (ASE, Dionex ASE 200, Thermo Scientific) equipped with $11 \mathrm{~mL}$ stainless steel extraction cells. The extraction conditions were as follows: solvent: hexane/acetone (1:1, v:v); oven heat up time: $6 \mathrm{~min}$; final temperature: $100{ }^{\circ} \mathrm{C}$; static time: 3 min; pressure: 1500 psi; purge time: 60 s; flush volume: $60 \%$; static extraction cycles:

3. The collected extracts were evaporated to dryness using a TurboVap concentrator (TurboVap II, Biotage, Sweden). Dried extracts were re-dissolved in $1 \mathrm{~mL}$ hexane for further clean-up.

Plant samples were rinsed thoroughly with Milli-Q water and then divided into root, stem, leaf, spike and grain. The plant samples were frozen at $-20{ }^{\circ} \mathrm{C}$ overnight and afterwards freeze-dried in a freeze-dryer at $-35{ }^{\circ} \mathrm{C}$ and 0.310 mbar for $48 \mathrm{~h}$. Dried plant samples were

powdered using a grinder (Retsch Ultrazentrifugalmühle, Retsch GmbH, Germany). Around 2-3 g of the prepared plant samples were extracted by ASE equipped with $22 \mathrm{~mL}$ 
stainless steel extraction cells. The extraction conditions were as follows: solvent: hexane/acetone (1:1, v:v); oven heat up time: $6 \mathrm{~min}$; final temperature: $125^{\circ} \mathrm{C}$; static time: 3 min; pressure: 1500 psi; purge time: 60 s; flush volume: $60 \%$; static extraction cycles: 3. The plant extracts were transferred into $50-\mathrm{mL}$ round bottom flask, and then solvent was evaporated in a rotary evaporator at $40^{\circ} \mathrm{C}$. A small amount of DCM was added to redissolve the extracted materials. Then a small amount of Florisil was added to absorb the extracted materials and the DCM extract was evaporated to dryness for further clean-up.

Column chromatography was used to purify the final extracts. For soil samples, a glass Pasteur pipette $(0.7 \mathrm{~cm}$ diameter $\times 15 \mathrm{~cm}$ length $)$ was packed from bottom to top with glass wool, $1 \mathrm{~cm}$ clean sea sand, $1 \mathrm{~g}$ activated Florisil, and a $0.5 \mathrm{~cm}$ layer of activated anhydrous $\mathrm{Na}_{2} \mathrm{SO}_{4}$. Anhydrous $\mathrm{Na}_{2} \mathrm{SO}_{4}$ was activated by heating at $200{ }^{\circ} \mathrm{C}$ overnight and saved in a closed container. Florisil was activated at $120^{\circ} \mathrm{C}$ for $12 \mathrm{~h}$ before usage. Chromatographic columns were pre-conditioned with $1 \mathrm{~mL}$ hexane. Afterwards $50 \mu \mathrm{g}$ 7,12-dimethylbenz $[\alpha]$ anthracene $\left(2 \mathrm{mg} \mathrm{mL}^{-1}\right.$ stock solution in hexane) was added on the top of the column. The fluorescence tracer co-elutes with HCHs and thus can be used as an indicator of the HCHs elution when using a UVA lamp. The HCH extracts were loaded onto the column and eluted continuously by adding $5 \mathrm{~mL}$ hexane (1st fraction) and $5-7 \mathrm{~mL}$ of a hexane/DCM mixture (v/v 1:1) (2nd fraction) at natural gravity flow velocity. The collection of the 2nd fraction was cut-off after the fluorescence band was eluted from the column. The eluate from the 1st fraction containing mainly hydrocarbons was disposed. The eluate from the 2nd fraction containing HCHs was reduced to $\sim 0.5 \mathrm{~mL}$ under a gentle $\mathrm{N}_{2}$ stream, and then transferred into a glass vial and adjusted to a final volume $1 \mathrm{~mL}$ by adding hexane for concentration and isotope analysis. 
For plant samples, a glass column $(2.2 \mathrm{~cm}$ diameter $\times 32.5 \mathrm{~cm}$ length $)$ was packed, from bottom to top, with glass wool as filter, $1 \mathrm{~cm}$ clean sea sand, $15 \mathrm{~cm}$ activated Florisil and $4 \mathrm{~cm}$ activated anhydrous $\mathrm{Na}_{2} \mathrm{SO}_{4}$. Florisil was packed into the column as a slurry dissolved in hexane to ensure that the column is tightly and homogeneously packed. Prior to usage of the column, $15 \mathrm{~mL}$ hexane was passed through the packed column. Afterwards, $100 \mu \mathrm{g}$ 7,12-dimethyl-benz[a]anthracene ( $2 \mathrm{mg} \mathrm{mL}^{-1}$ stock solution in hexane) was added on the top of the column as a UV-tracer. The HCH extracts were loaded onto the column and eluted continuously by adding $30 \mathrm{~mL}$ hexane (1st fraction) and $50 \mathrm{~mL}$ of a hexane/DCM mixture (v/v 1:1) (2nd fraction). The 1st fraction was discharged and the 2nd fraction containing quantitatively HCHs was concentrated under a gentle $\mathrm{N}_{2}$ stream in a TurboVap concentrator. The concentrated samples were transferred into glass vials using glass pipettes and re-constituted into $1 \mathrm{~mL}$ using hexane for concentration and isotope analysis. 


\section{S4 Analytical Methods}

The isotopic composition of an element $(\mathrm{E})$ was reported as $\delta$ notation in parts per thousand (\%) relative to the international standard scale according to eq 1.

$$
\delta E_{\text {sample }}(\%)=\frac{R_{\text {sample }}}{R_{\text {standard }}}-1
$$

$\mathrm{R}_{\text {sample and }} \mathrm{R}_{\text {standard }}$ are the ${ }^{13} \mathrm{C} /{ }^{12} \mathrm{C}$ and ${ }^{37} \mathrm{Cl} /{ }^{35} \mathrm{Cl}$ ratios of the sample and the standard, respectively.

Concentration Analysis. HCHs were separated with a HP-5 column $(30 \mathrm{~m} \times 320 \mu \mathrm{m} \times 0.25$ $\mu \mathrm{m}$, Agilent 19091J-413, USA) using helium as carrier gas with a flow rate of $2.2 \mathrm{~mL} \mathrm{~min}^{-}$

${ }^{1}$. The oven temperature program was initially held at $45^{\circ} \mathrm{C}$ for $5 \mathrm{~min}$, increased at $8{ }^{\circ} \mathrm{C}$ $\min ^{-1}$ to $180{ }^{\circ} \mathrm{C}$ and then at $2{ }^{\circ} \mathrm{C} \min ^{-1}$ to $195{ }^{\circ} \mathrm{C}$, and finally increased at $8{ }^{\circ} \mathrm{C} \mathrm{min}{ }^{-1}$ to $220^{\circ} \mathrm{C}$ with a hold of $2 \mathrm{~min}$. Samples were measured using splitless mode with an injector temperature of $250{ }^{\circ} \mathrm{C}$. The injection volume was $1 \mu \mathrm{L}$. Each sample was measured in triplicates.

Isotope Analysis. Carbon isotopic composition. A Zebron ZB1 column $(60 \mathrm{~m} \times 0.32 \mathrm{~mm}$ $\times 1 \mu \mathrm{m}$; Phenomenex, Germany) with a constant carrier gas flow of $2 \mathrm{~mL} \mathrm{~min}^{-1}$ was applied for chromatographic separation. The oven temperature was initially held at $40^{\circ} \mathrm{C}$ for $5 \mathrm{~min}$, increased at $10{ }^{\circ} \mathrm{C} \min ^{-1}$ to $175{ }^{\circ} \mathrm{C}$ and then at $2{ }^{\circ} \mathrm{C} \min ^{-1}$ to $200{ }^{\circ} \mathrm{C}$ with a hold of $10 \mathrm{~min}$, and finally increased at $15^{\circ} \mathrm{C} \mathrm{min}-1$ to $300^{\circ} \mathrm{C}$ and held for $2 \mathrm{~min}$. All samples were injected in splitless mode into a split/splitless injector hold at $250^{\circ} \mathrm{C}$. Each sample was analyzed in triplicates. The quality of the isotope data was controlled by analyzing a HCH standard with of known isotopic composition, as described elsewhere ${ }^{2}$. 
Chlorine isotopic composition. A gas chromatograph (Trace 1310, Thermo Fisher Scientific, Germany), equipped with an auto-sampler (TriPlus RSH, Thermo Fisher Scientific, Germany) was used for separation. Samples were injected in splitless mode with

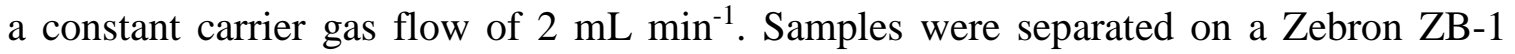
column using the same temperature program as described for the carbon isotope ratio measurement. Trichloroethene used as in-house reference compound $\left(\mathrm{TCE} 2, \delta^{37} \mathrm{Cl}=\right.$ $-1.19 \%$ ) was added to each sample as an internal isotopic reference for identifying potential instrumental drifts. The $\delta^{37} \mathrm{Cl}$ was determined in two steps: (1) the deviation of a sample from the internal standard TCE2 was calculated, and (2) raw $\delta^{37} \mathrm{Cl}$ values were calibrated to SMOC scale by applying a two-point calibration approach. Calibration to SMOC scale was done using in-house standards with confirmed off-line chlorine isotopic compositions, including methyl chloride $\left(\mathrm{MeCl}, \delta^{37} \mathrm{Cl}=+6.02 \%\right)$ and trichloroethene (TCE2, $\delta^{37} \mathrm{Cl}=-1.19 \%$ ). In addition, trichloroethene (TCE6, $\delta^{37} \mathrm{Cl}=+2.17 \%$ ) and tetrachloroethene (PCE1, $\delta^{37} \mathrm{Cl}=-0.55 \%$ ) were used for the validation of calibration, as described by Horst et al ${ }^{3}$.

Metabolites analysis. The components of soil and plant samples were separated with a ZB1 column using a helium flow of $1 \mathrm{~mL} \mathrm{~min}^{-1}$ as carrier gas. The oven temperature program was initially held at $40{ }^{\circ} \mathrm{C}$ for $2 \mathrm{~min}$, increased at $10{ }^{\circ} \mathrm{C} \mathrm{min}-1$ to $200^{\circ} \mathrm{C}$ and then at $2{ }^{\circ} \mathrm{C}$ $\min ^{-1}$ to $230{ }^{\circ} \mathrm{C}$, and finally increased at $20^{\circ} \mathrm{C} \min ^{-1}$ to $300{ }^{\circ} \mathrm{C}$ and held for $10 \mathrm{~min}$. All samples were injected in split (1:1) mode into a hot injector hold at $250{ }^{\circ} \mathrm{C}$.

Bioconcentration factors. Bioconcentration factors (BCFs) for root (RCF), stem (SCF), leaf (LCF), spike (SPCF) and grain (GCF) were calculated as the ratio between the HCH concentration of the different wheat tissues (Con tissue) and the host bulk soil (Conbulk soil) at 
the same growth stage to study the translocation of $\mathrm{HCH}$ in plants. The HCH concentration normalized to dry weight was used for the calculation according to eq 2.

$$
B C F s=\frac{\text { Con.(tissue })}{\text { Con.(bulk soil })}
$$

Metagenomics Analysis. High-quality cleaned data (Table S1, SI) were processed for the taxonomic characterization by comparing the reads nr database of the Kaiju program using the mem run mode ${ }^{4}$ at phylum and genus taxonomic levels. The diversity at the genus level was plotted using hclust2 (https://github.com/SegataLab/hclust2). Reads for the three metagenomes were assembled into contigs using IDBA_UD assembler (v 1.1.3) using minimum and maximum k-mer lengths of 41 and 101, respectively ${ }^{5}$. The metagenomes were annotated against the subsystems, KEGG, NOG, and COG databases using MGRAST version $4{ }^{6}$. The heatmaps for functional analyses based on the presence of xenobiotics biodegradation and metabolism and presence of oxygenases that play an important role in the degradation were plotted using the Clustvis tool ${ }^{7}$. Rows were centered until variance scaling was applied to rows. Both rows and columns were clustered using correlation distance and average linage. 
S5 Metabolites Analysis

The possible metabolites of $\beta$-HCH were measured by GC-MS. Several metabolites including pentachlorocyclohexene isomers, tetrachlorocyclohexene isomers, trichlorobenzene isomers, dichlorobenzene isomers, chlorobenzene were detected in soil and plant samples in pot experiments (Fig.S4), suggesting the transformation of $\beta-\mathrm{HCH}$ in the soil-plant systems. The pentachlorocyclohexene isomers, trichlorobenzene, trichlorobenzene isomers are typical aerobic transformation products of $\mathrm{HCH}$ and the tetrachlorocyclohexene isomers, dichlorobenzene isomers, chlorobenzene are also found in anaerobic transformation of $\mathrm{HCH}$. The qualitative appearance of metabolites in plant is similar as in soil, suggesting the degrading bacteria may be similar and have similar transformation pathways. However, it is difficult to draw the conclusion if the transformation took place within the plants since the metabolites may be already in the soil before the new-spiking $\beta$-HCH or formed by the soil microbiome. The transformation products have all higher water solubility and may be picked up with water. Thus only the appearance of transformation products even in plants do not prove the transformation in plants but may give an indication that in the soil-plant system transformation takes place. However in the current system CSIA can give us strong indication of transformation in the complex systems, as the isotope enrichment from root to leave showed the transformation indeed takes place in the plants. 
S6 Additional homologous sequence hits from the metagenome data

In addition to lin genes, hits to several open reading frames (orfs) reported from the pLINA57 cosmid region from S. indicum B90A were also detected. These orfs coded for phospholipase (orfX), dehydrogenases (orfG and orfH), cytochrome-c-oxidase (orfQ, orfP and orfR), IS600 transposase (TnpA4), outer membrane protein (orfN), outer membrane receptor, and transport proteins (orfO, orf1, orfU), putative glutathione transferase (orfS), putative glutathione transferase (orf6) and phospholipase (orfX) (Supplementary Table 1). These genes are important for the degradation of $\mathrm{HCH}$ and the transposon has been reported to induce horizontal gene transfer of these catabolic genes. 


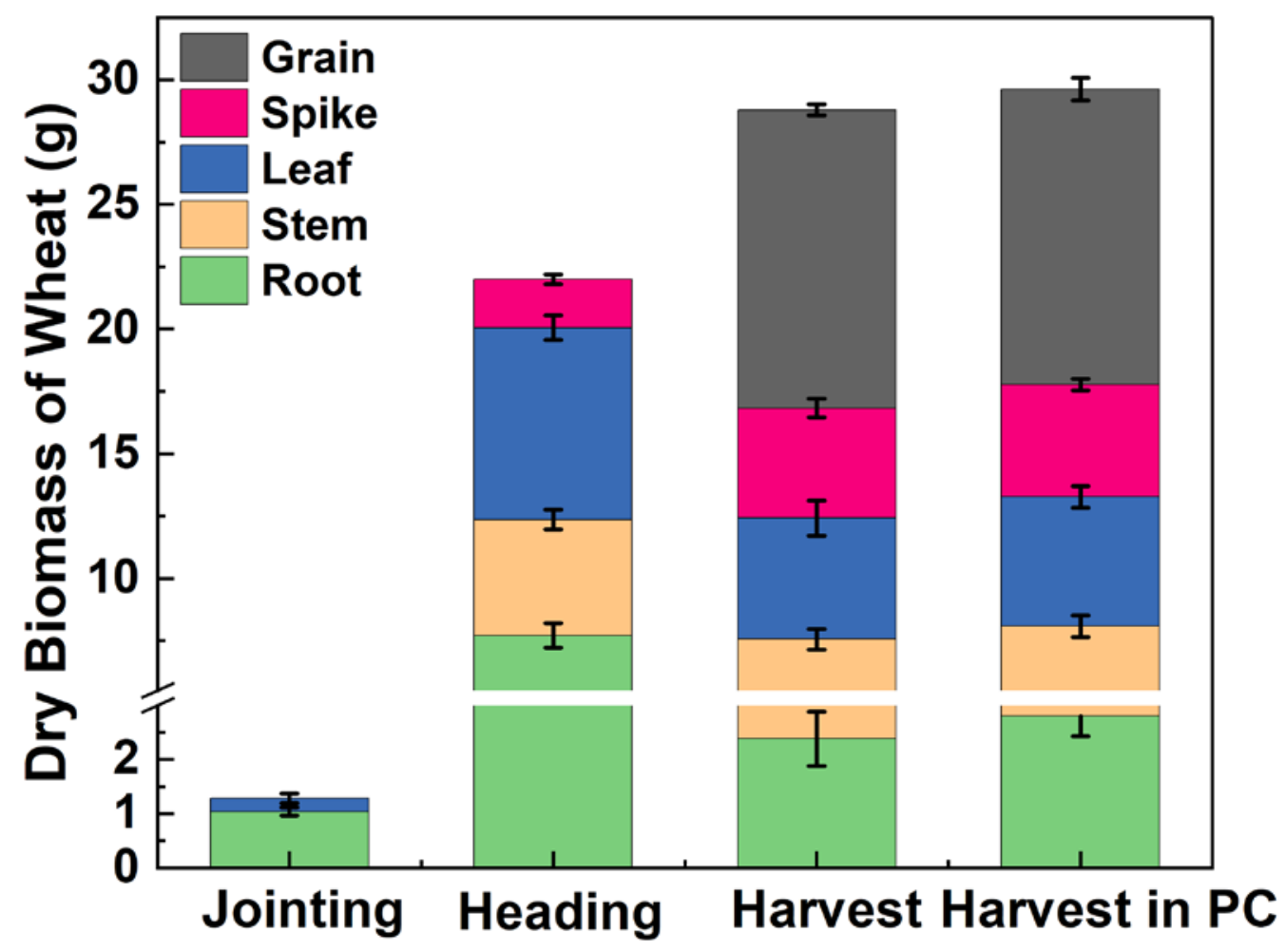

Figure S1. Biomass of different wheat tissues at different growth stages of spiked treatments in comparison to wheat biomass at the harvest stage of the planted control (PC: planted control). 

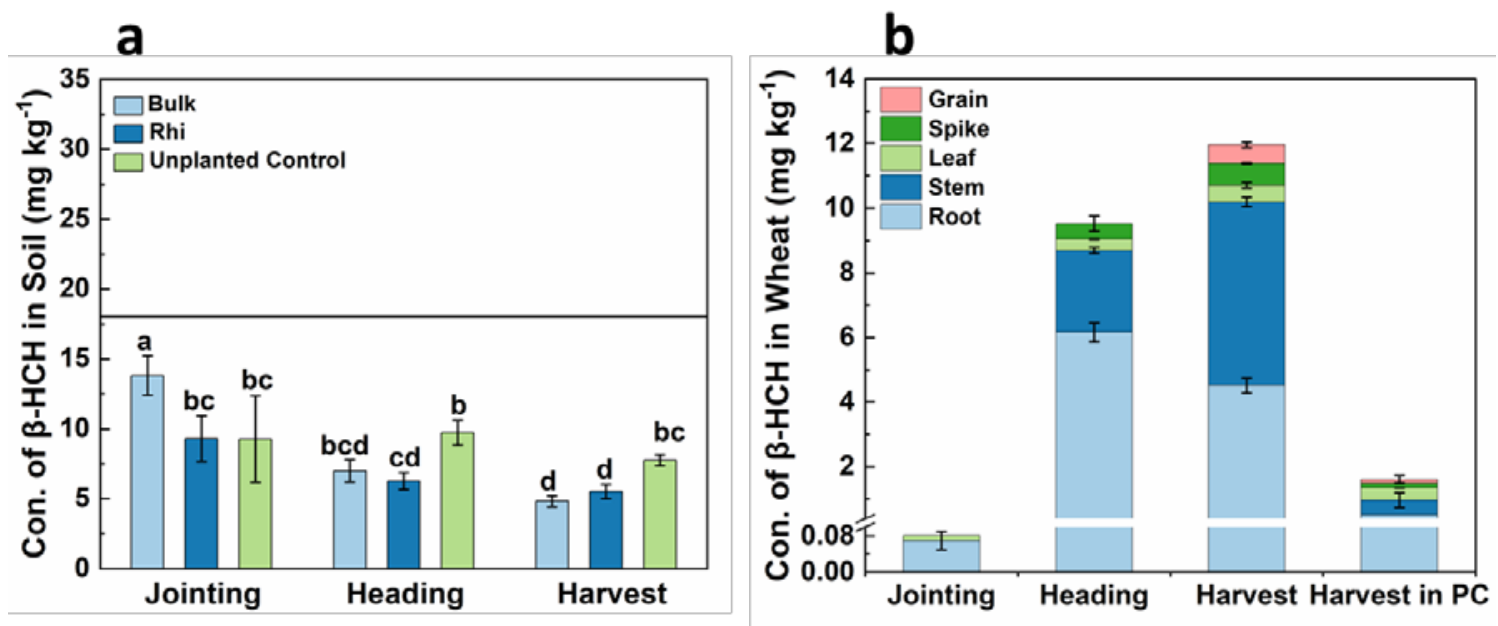

Figure S2. Concentration of $\beta-\mathrm{HCH}$ in soil at different growth stages in the spiked treatment and the unplanted control (a) and concentration of $\beta-\mathrm{HCH}$ in different wheat tissues at different growth stages in the spiked treatment and the harvest stage of the planted control (b). The line in figure a represents the initial $\beta$ - $\mathrm{HCH}$ concentration of the spiked treatment and the unplanted control. Bulk: bulk soil. Rhi: rhizosphere soil. PC: planted control. The letters (a-d) in figure a represent statistically significant difference between soil samples at different growth stages according to Fisher's least significant difference test (LSD) $(p<0.05)$. Error bars represent SD values. 


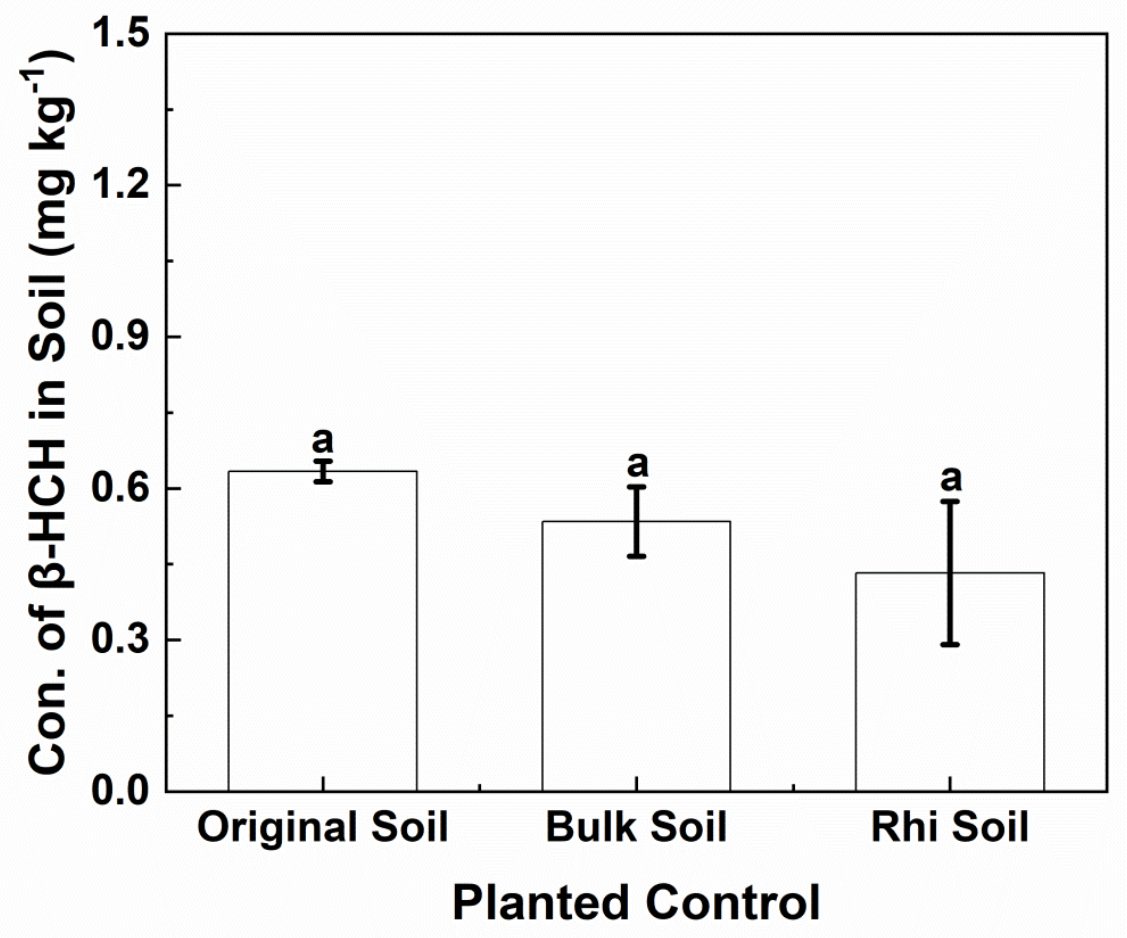

Figure S3. Concentration of $\beta$-HCH in soil at the harvest stage of the planted control. The original soil means the concentration of $\beta-\mathrm{HCH}$ of the native contaminated soil. Rhi: rhizosphere. The letters in all figures represent statistically significant difference between soil samples at different growth stages according to Fisher's least significant difference test (LSD) $(p<0.05)$. Error bars represent SD values. 

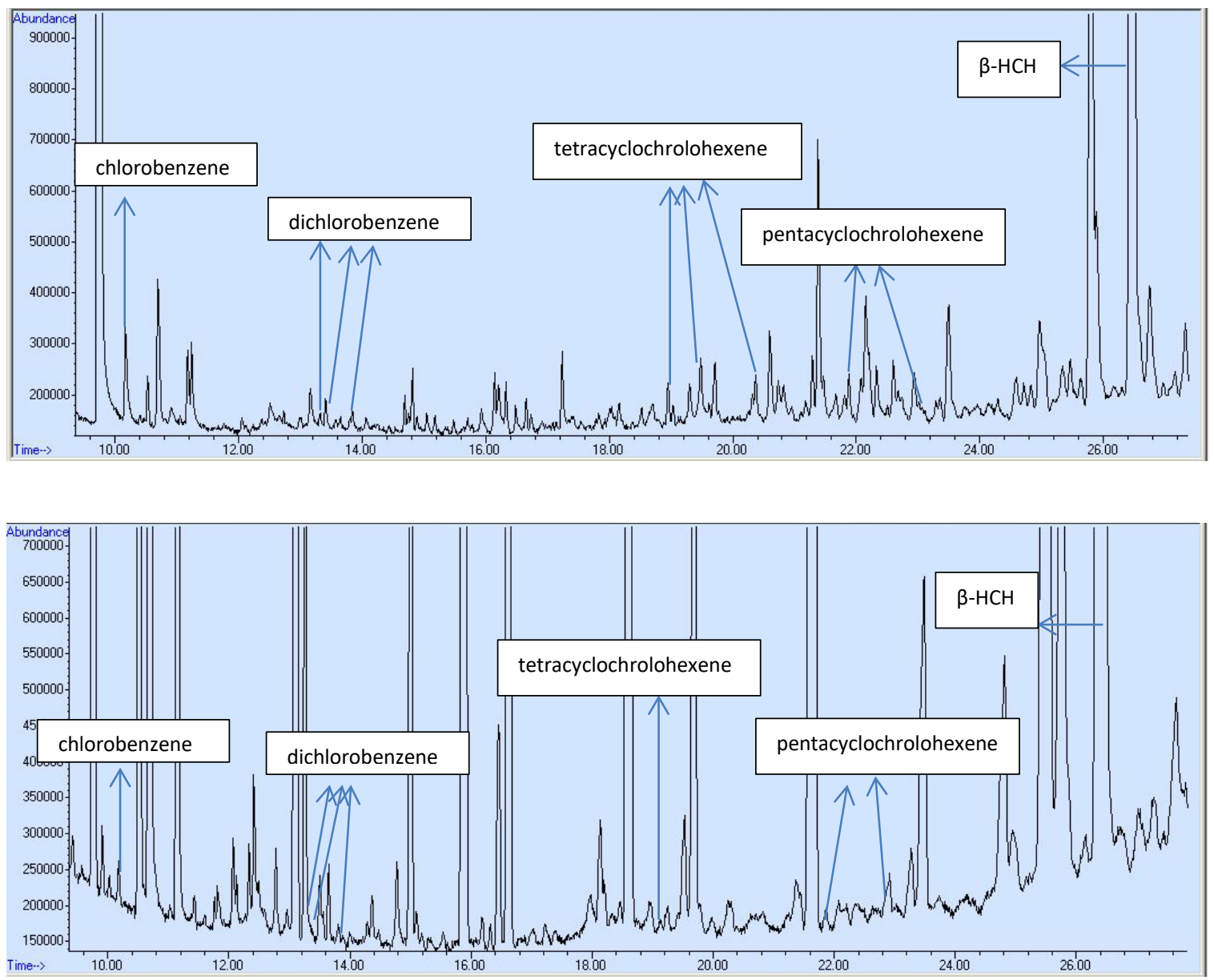

Figure S4. The chromatography of selected bulk soil sample in jointing stage in spiked treatment (a) and selected root sample in heading stage (b) measured by GC-MS. 


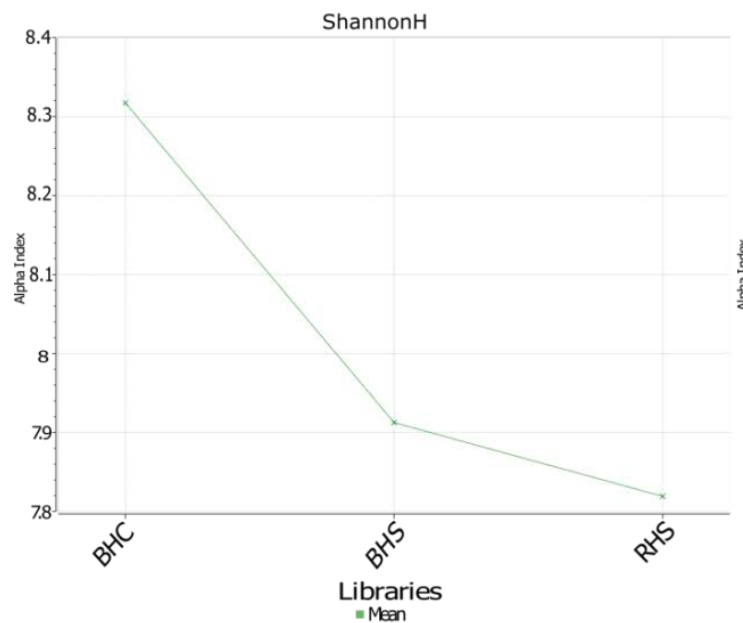

(A)

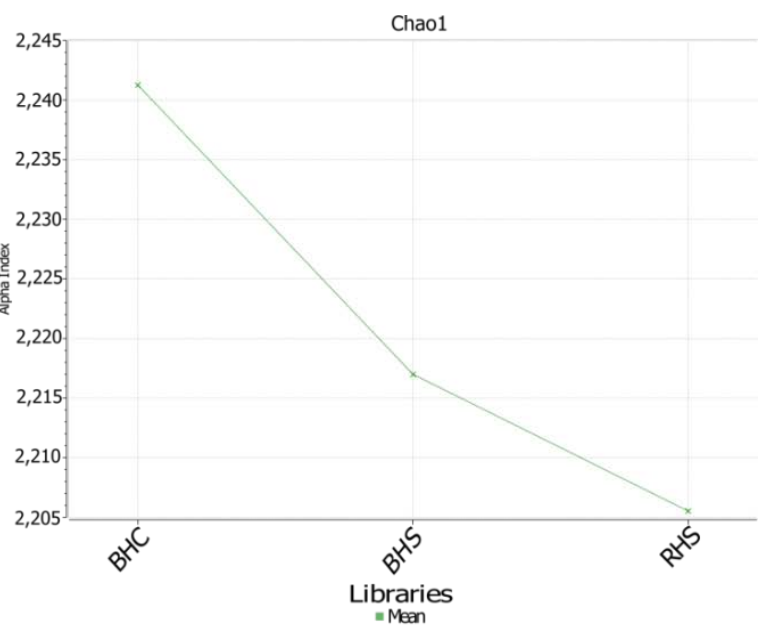

(B)

Figure S5. Alpha-diversity analysis of the three soil samples based on ShannonH (A) and Chao1 index (B) at the harvest stage. BHC: bulk soil spiked with $\beta$-HCH without wheat (unplanted control) at the harvest stage. BHS: bulk soil spiked with $\beta$-HCH with wheat (spiked treatment) at the harvest stage. RHS: rhizosphere soil spiked with $\beta$-HCH with wheat (spiked treatment) at the harvest stage. All three soils were rich in bacterial diversity, however, BHC had a slightly increased diversity of bacteria. 


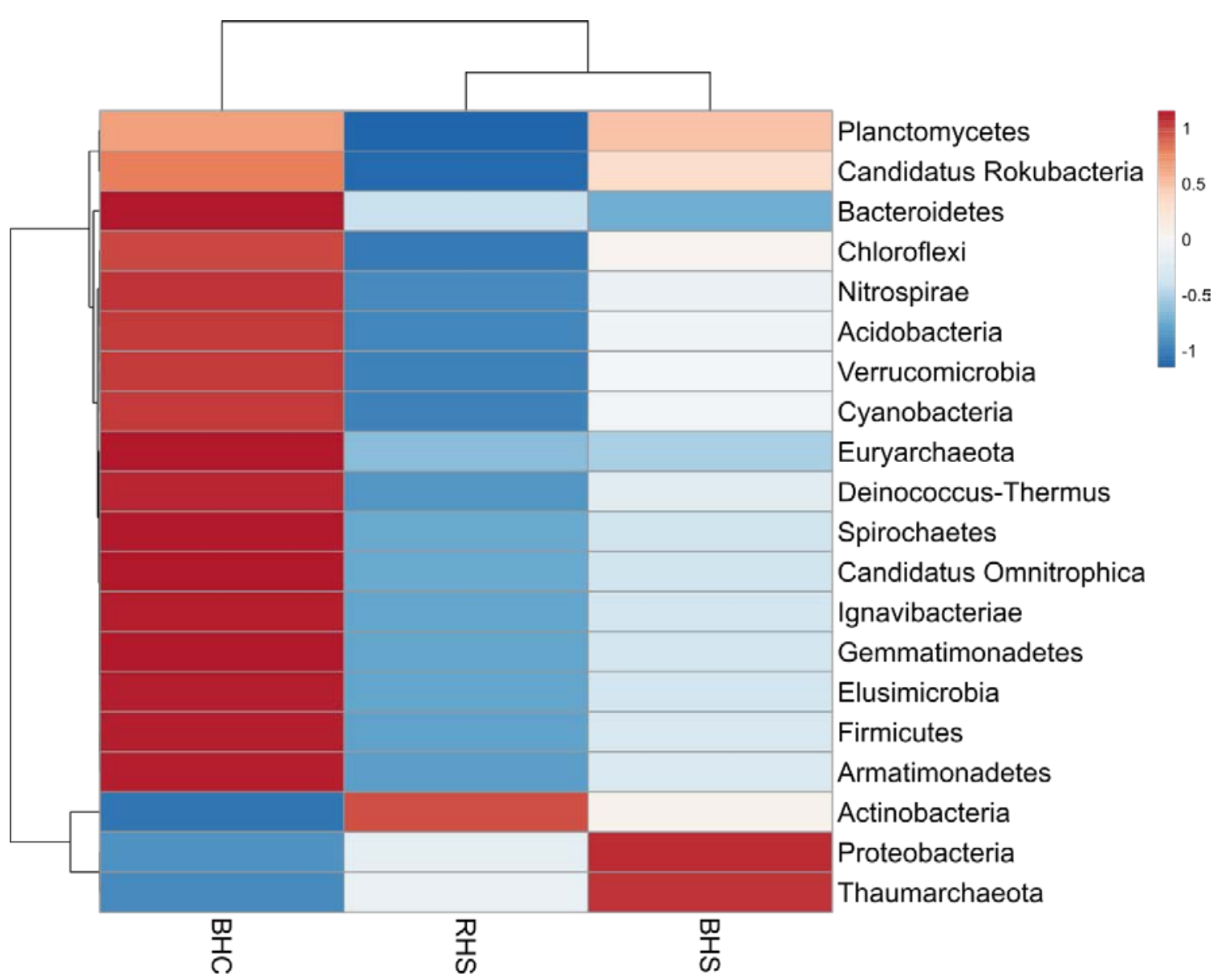

Figure S6. Heatmap of the relative abundance of the top 20 phyla in the soil samples at the harvest stage. BHC: bulk soil spiked with $\beta-\mathrm{HCH}$ without wheat (unplanted control) at the harvest stage. BHS: bulk soil spiked with $\beta-\mathrm{HCH}$ with wheat (spiked treatment) at the harvest stage. RHS: rhizosphere soil spiked with $\beta$-HCH with wheat (spiked treatment) at the harvest stage. 

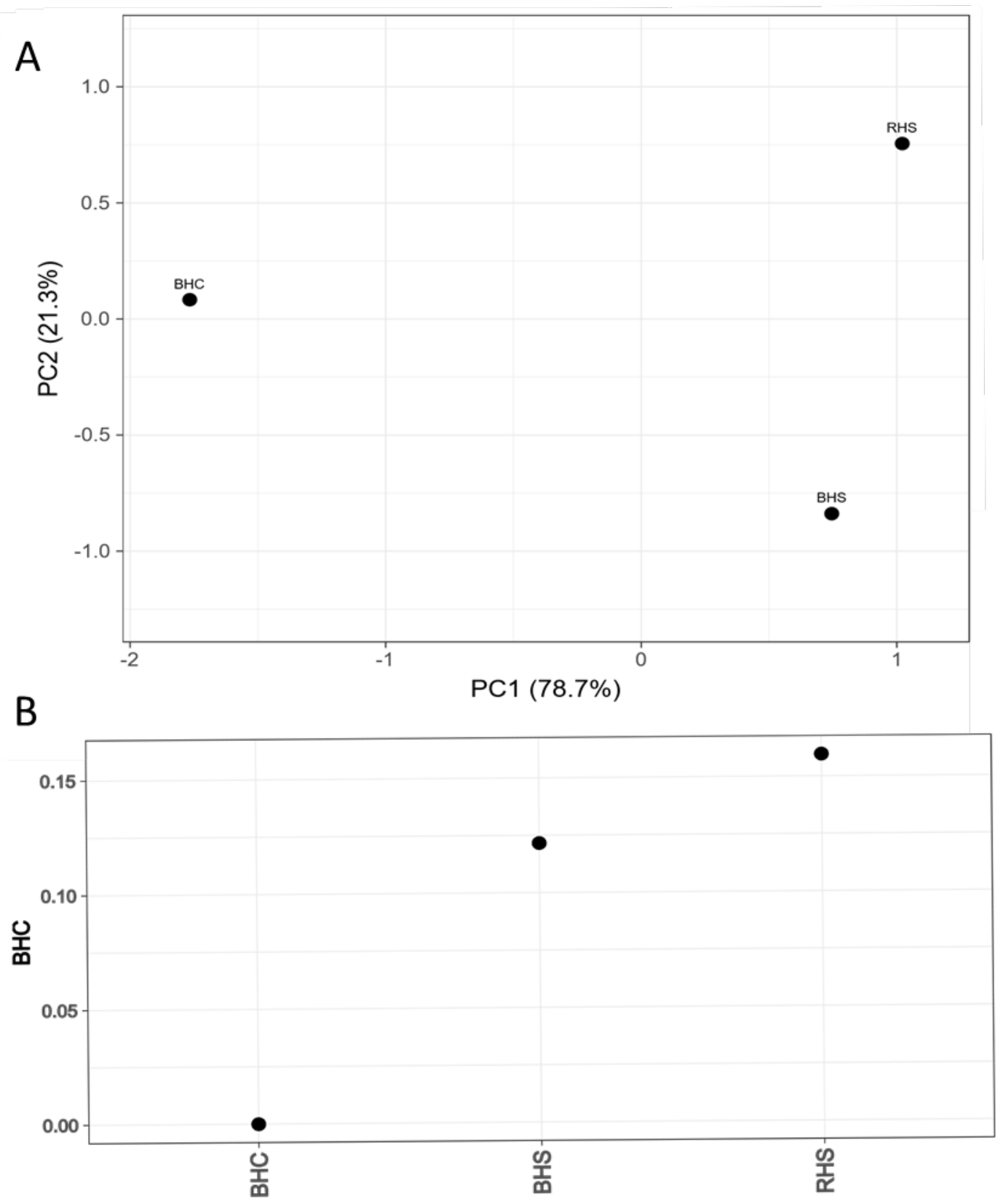

Figure S7. (A) Principal component analysis (PCoA) based beta diversity of soil samples at the harvest stage. (B) The plot represents the beta-diversity value based on Bray-Curtis dissimilarity values. The Bray-Curtis dissimilarity is bounded between 0 and 1 , where 0 means the two sites have the same composition (that is they share all the species), and 1 means the two sites do not share any species BHC: bulk soil spiked with $\beta$-HCH without 
wheat (unplanted control) at the harvest stage. BHS: bulk soil spiked with $\beta$-HCH with wheat (spiked treatment) at the harvest stage. RHS: rhizosphere soil spiked with $\beta-\mathrm{HCH}$ with wheat (spiked treatment) at the harvest stage. BHS and RHS were more closely related. 

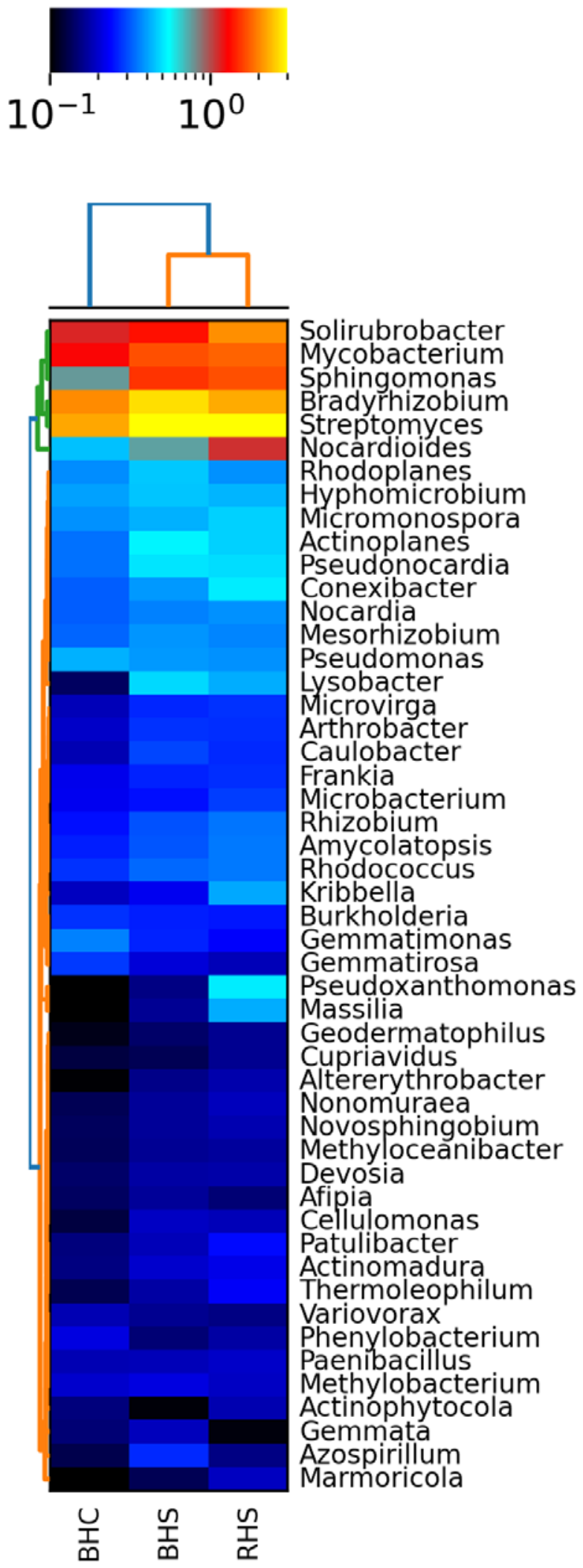
Figure S8. Heatmap of the relative abundance of the top 50 genera in the soil samples at the harvest stage. BHC: bulk soil spiked with $\beta-\mathrm{HCH}$ without wheat (unplanted control) at the harvest stage. BHS: bulk soil spiked with $\beta-\mathrm{HCH}$ with wheat (spiked treatment) at the harvest stage. RHS: rhizosphere soil spiked with $\beta-\mathrm{HCH}$ with wheat (spiked treatment) at the harvest stage. 


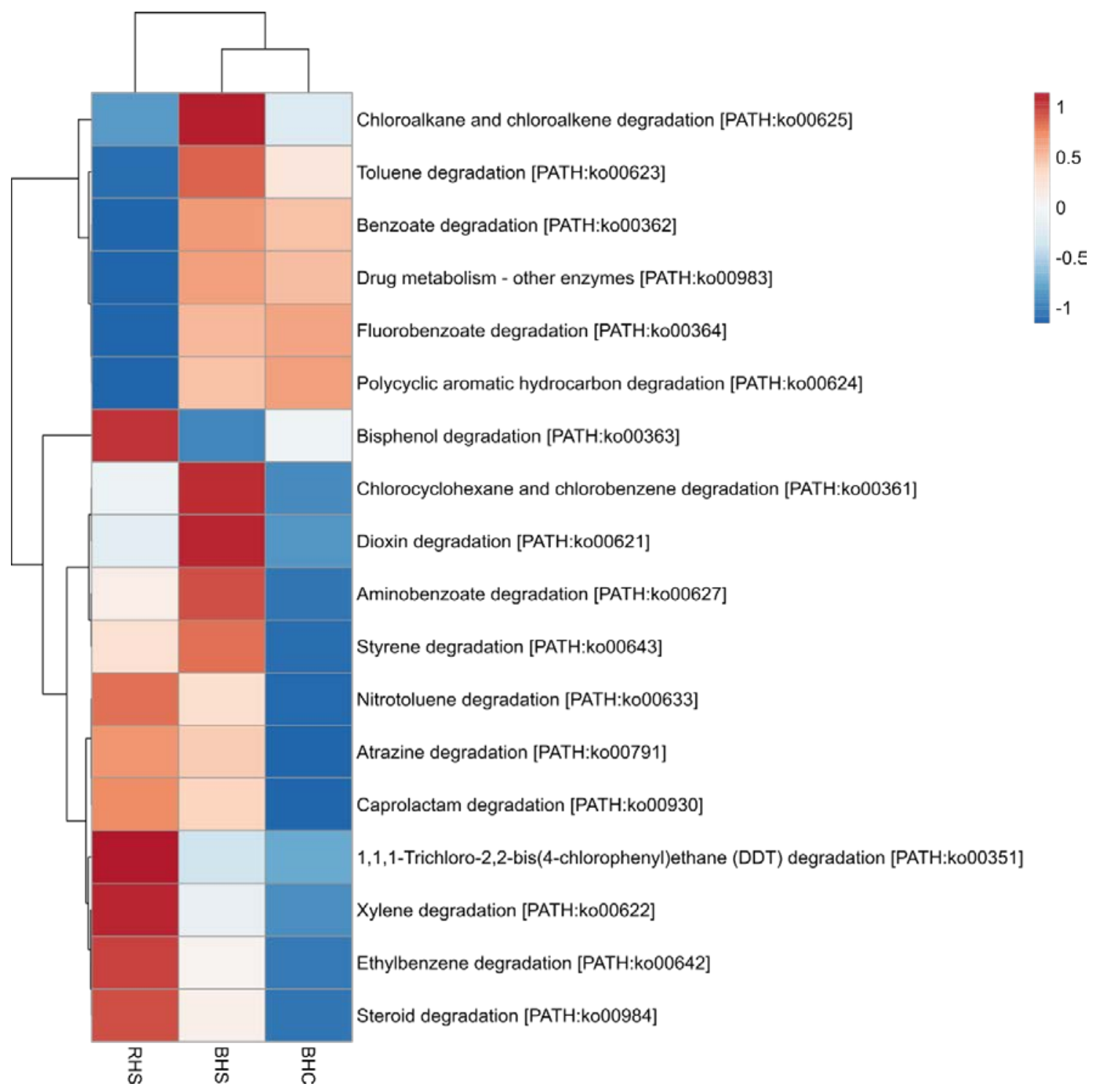

Figure S9. Relative abundance of xenobiotic degradation pathway in $\beta-\mathrm{HCH}$ treated soil at the harvest stage. BHC: bulk soil spiked with $\beta-\mathrm{HCH}$ without wheat (unplanted control) at the harvest stage. BHS: bulk soil spiked with $\beta-\mathrm{HCH}$ with wheat (spiked treatment) at the harvest stage. RHS: rhizosphere soil spiked with $\beta$-HCH with wheat (spiked treatment) at the harvest stage. BHS and RHS had more abundant degradation pathways when compared against BHC implying better degradation potential of soil in the potted plant. 


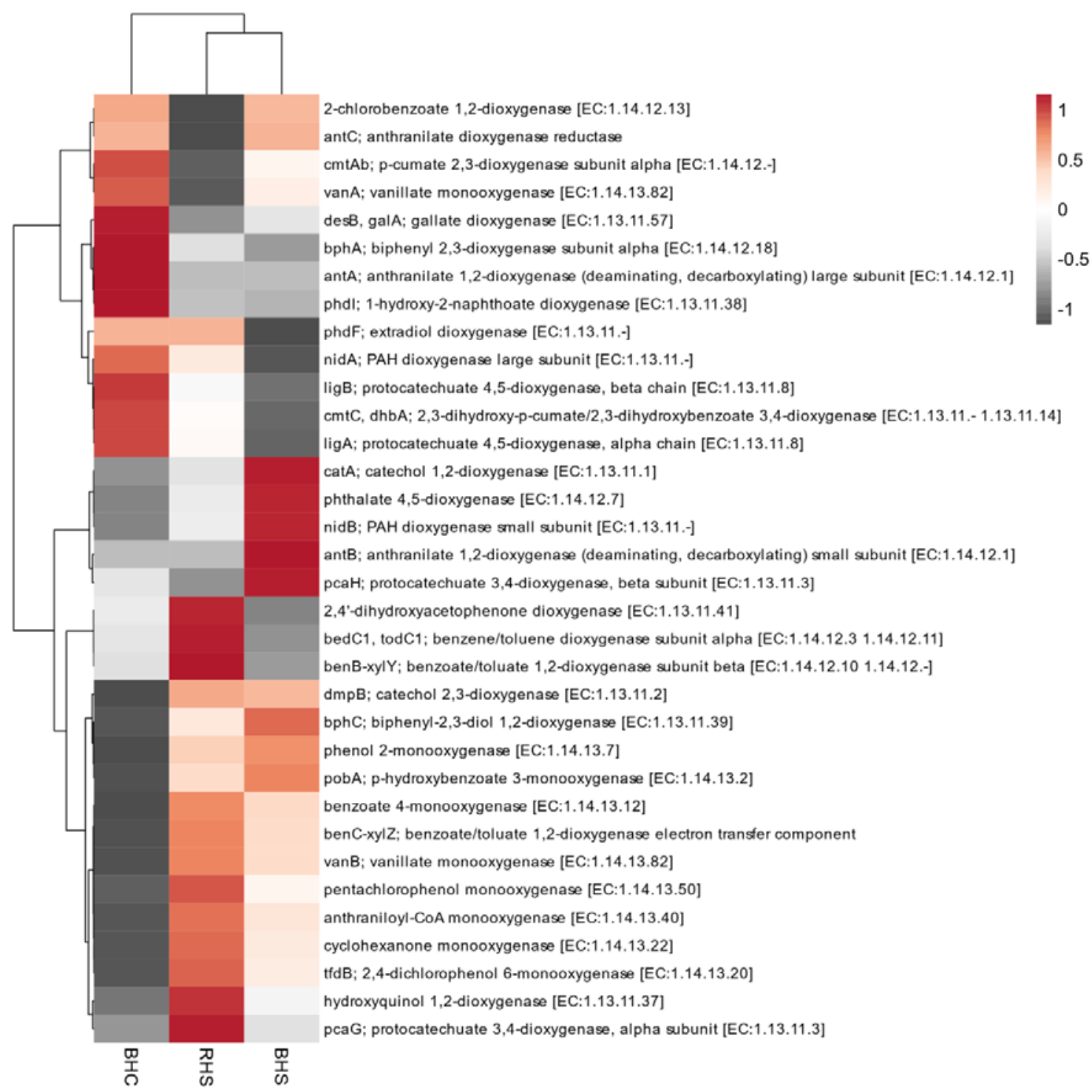

Figure S10. Relative abundance of oxygenases in $\beta-\mathrm{HCH}$ treated soil at the harvest stage. BHC: bulk soil spiked with $\beta-\mathrm{HCH}$ without wheat (unplanted control) at the harvest stage. BHS: bulk soil spiked with $\beta$-HCH with wheat (spiked treatment) at the harvest stage. RHS: rhizosphere soil spiked with $\beta$-HCH with wheat (spiked treatment) at the harvest stage. BHS and RHS had more abundant mono and di-oxygenase when compared against BHC implying better degradation potential of soil in the potted plant. 
Table S1. BCFs of $\beta-\mathrm{HCH}$ in different wheat tissues at different growth stages.

\begin{tabular}{ccccc}
\hline & & Spiked treatment & & Planted control \\
& Jointing & Heading & Harvest & Harvest \\
\hline LCF & 0.0001 & 0.051 & 0.108 & 0.282 \\
SCF & - & 0.363 & 1.175 & 0.842 \\
RCF & 0.005 & 0.882 & 0.935 & 0.973 \\
SPCF & - & 0.068 & 0.139 & 0.247 \\
GCF & - & - & 0.118 & 0.243 \\
\hline
\end{tabular}

“-“: no value because of missing biomass

LCF: leaf bioconcentration factor; SCF: stem bioconcentration factor; RCF: root bioconcentration factor; SPCF: spike bioconcentration factor; GCF: grain bioconcentration factor. 
Table S2 The data statistics of the metagenome analysis

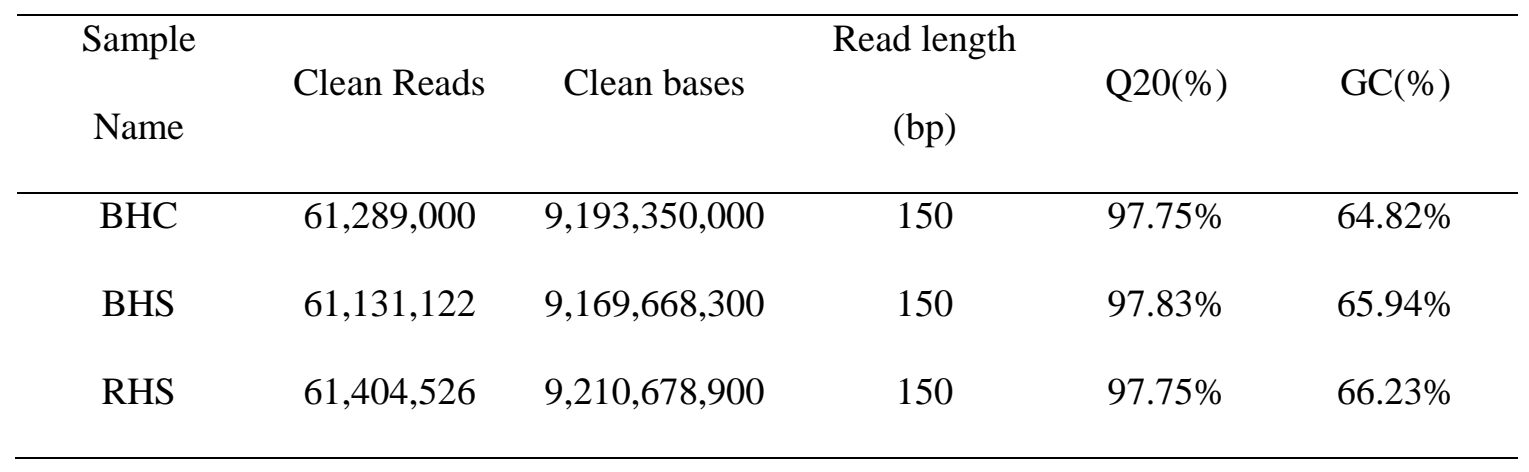

BHC: bulk soil spiked with $\beta-\mathrm{HCH}$ without wheat (unplanted control) at the harvest stage. BHS: bulk soil spiked with $\beta-\mathrm{HCH}$ with wheat (spiked treatment) at the harvest stage. RHS: rhizosphere soil spiked with $\beta$ $\mathrm{HCH}$ with wheat (spiked treatment) at the harvest stage. 


\section{REFERENCES}

(1) Stollberg, R. Groundwater contaminant source zone identifica- tion at an industrial and abandoned mining site: a foren- sic backward-in-time modelling. Ph.D. Thesis. Naturwis- senschaftliche Fakult at III, Martin-Luther University Halle- Wittenberg 2013.

(2) Liu, Y.; Bashir, S.; Stollberg, R.; Trabitzsch, R.; Weiß, H.; Paschke, H.; Nijenhuis, I.; Richnow, H. H. Compound Specific and Enantioselective Stable Isotope Analysis as Tools to Monitor Transformation of Hexachlorocyclohexane (HCH) in a Complex Aquifer System. Environ. Sci. Technol. 2017, 51 (16), 8909-8916.

(3) Horst, A.; Renpenning, J.; Richnow, H. H.; Gehre, M. Compound Specific Stable Chlorine Isotopic Analysis of Volatile Aliphatic Compounds Using Gas Chromatography Hyphenated with Multiple Collector Inductively Coupled Plasma Mass Spectrometry. Anal. Chem. 2017, 89, 9131-9138.

(4) Menzel, P.; Ng, K. L.; Krogh, A. Fast and Sensitive Taxonomic Classification for Metagenomics with Kaiju. Nat. Commun. 2016, 7, 1-9.

(5) Peng, Y.; Leung, H. C. M.; Yiu, S. M.; Chin, F. Y. L. IDBA-UD: A de Novo Assembler for SingleCell and Metagenomic Sequencing Data with Highly Uneven Depth. Bioinformatics 2012, 28 (11), $1420-1428$.

(6) Meyer, F.; Bagchi, S.; Chaterji, S.; Gerlach, W.; Grama, A.; Harrison, T.; Paczian, T.; Trimble, W. L.; Wilke, A. MG-RAST Version 4-Lessons Learned from a Decade of Low-Budget Ultra-HighThroughput Metagenome Analysis. Brief. Bioinform. 2018, 20 (4), 1151-1159.

(7) Metsalu, T.; Vilo, J. ClustVis: A Web Tool for Visualizing Clustering of Multivariate Data Using Principal Component Analysis and Heatmap. Nucleic Acids Res. 2015, 43 (W1), W566-W570. 